OPEN ACCESS

Edited by:

Wanjun Chen,

National Institutes of Health (NIH),

United States

Reviewed by:

David Hildeman,

Cincinnati Children's Hospital Medical

Center, United States

Aleš Janda,

Universitätsklinikum Freiburg-Albert Ludwigs Universität Freiburg,

Germany

*Correspondence:

Frederic Rieux-Laucat

frederic.rieux-laucat@inserm.fr

Specialty section:

This article was submitted to

T Cell Biology,

a section of the journal

Frontiers in Immunology

Received: 05 September 2017

Accepted: 22 March 2018

Published: 09 April 2018

Citation:

Mazerolles F, Stolzenberg M-C,

Pelle O, Picard C, Neven B, Fischer $A$, Magerus-Chatinet $A$ and Rieux-Laucat $F$ (2018) Autoimmune Lymphoproliferative Syndrome-FAS

Patients Have an Abnormal Regulatory T Cell (Treg) Phenotype

but Display Normal Natural

Treg-Suppressive Function on

$T$ Cell Proliferation.

Front. Immunol. 9:718.

doi: 10.3389/fimmu.2018.00718

\section{Autoimmune Lymphoproliferative Syndrome-FAS Patients Have an Abnormal Regulatory T Cell (Treg) Phenotype but Display Normal Natural Treg-Suppressive Function on T Cell Proliferation}

\author{
Fabienne Mazerolles ${ }^{1,2}$, Marie-Claude Stolzenberg ${ }^{1,2}$, Olivier Pelle ${ }^{1,3}$, Capucine Picard ${ }^{2,4,5,6}$, \\ Benedicte Neven ${ }^{1,2,4}$, Alain Fischer ${ }^{2,4,7}$, Aude Magerus-Chatinet ${ }^{1,2}$ \\ and Frederic Rieux-Laucat ${ }^{1,2 *}$

\begin{abstract}
'INSERM UMR1163, Laboratory of Immunogenetics of Paediatric Autoimmunity, Paris, France, ${ }^{2}$ Paris Descartes - Sorbonne Paris Cité University, Imagine Institute Paris, Paris, France, ${ }^{3}$ INSERM UMR1163, Cell Sorting Facility, Paris, France, ${ }^{4}$ Paediatric Haematology-Immunology and Rheumatology Unit, Necker-Enfants Malades Hospital, Assistance PubliqueHôpitaux de Paris (APHP), Paris, France, ${ }^{5}$ Center for Primary Immunodeficiencies, Necker-Enfants Malades Hospital, APHP, Paris, France, ${ }^{6}$ Laboratory of Lymphocyte Activation and Susceptibility to EBV Infection, INSERM UMR 1163, Imagine Institute, University Paris Descartes Sorbonne Paris Cité, Paris, France, ${ }^{7}$ Collège de France, Paris, France
\end{abstract}

Objective: Autoimmune lymphoproliferative syndrome (ALPS) with FAS mutation (ALPS-FAS) is a nonmalignant, noninfectious, lymphoproliferative disease with autoimmunity. Given the central role of natural regulatory T cells (nTregs) in the control of lymphoproliferation and autoimmunity, we assessed nTreg-suppressive function in 16 patients with ALPS-FAS.

Results: The proportion of CD2 $5^{\text {high }}$ CD127 low Tregs was lower in ALPS-FAS patients than in healthy controls. This subset was correlated with a reduced $\mathrm{CD} 25$ expression in $\mathrm{CD} 3^{+} \mathrm{CD} 4^{+}$ T cells from ALPS patients and thus an abnormally low proportion of CD25 high FOXP3+ Helios $^{+} \mathrm{T}$ cells. The ALPS patients also displayed a high proportion of naïve Treg (FOXP3 ${ }^{\text {low }}{ }^{\circ}$ 45RA $\left.{ }^{+}\right)$and an unusual subpopulation $\left(C D 4{ }^{+} C D 127^{\text {low }} \mathrm{CD} 15 \mathrm{~s}^{+} \mathrm{CD} 45 \mathrm{RA} \mathrm{A}^{+}\right)$. Despite this abnormal phenotype, the CD25 high CD127low Tregs' suppressive function was unaffected. Furthermore, conventional T cells from FAS-mutated patients showed normal levels of sensitivity to Treg suppression.

Conclusion: An abnormal Treg phenotype is observed in circulating lymphocytes of ALPS patients. However, these Tregs displayed a normal suppressive function on $T$ effector proliferation in vitro. This is suggesting that lymphoproliferation observed in ALPS patients does not result from Tregs functional defect or T effector cells insensitivity to Tregs suppression.

Keywords: human, autoimmune lymphoproliferative syndrome-FAS, cell proliferation, regulatory $\mathrm{T}$ cell, suppression assay

Abbreviations: ALPS, autoimmune lymphoproliferative syndrome; APC, antigen-presenting cell; CFSE, carboxyfluorescein succinimidyl ester; CT, healthy control; DC, dendritic cell; SEE, staphylococcal enterotoxin E; Treg, regulatory T cell; Tconv, conventional effector $\mathrm{T}$ cell. 


\section{INTRODUCTION}

Autoimmune lymphoproliferative syndrome (ALPS) is characterized by defective lymphocyte apoptosis and thus the dysregulation of lymphocyte homeostasis (1). In turn, this dysregulation leads to nonmalignant polyclonal lymphoproliferation and then splenomegaly, lymphadenopathy, and hepatomegaly. Autoimmune manifestations (mostly autoimmune hemolytic anemia, thrombocytopenia, and, in some cases, neutropenia) are observed in two-thirds of patients with ALPS (2). An elevated risk of lymphoma has also been reported. The characteristic laboratory abnormalities include the expansion of $\mathrm{T}$ cells that express the alpha/beta T cell receptor but lack both CD4 and CD8 in peripheral blood and tissue samples (i.e., doublenegative (DN) T cells) (3). These DNT cells have been shown to originate from the terminally differentiated effector memory $\mathrm{CD}_{45 \mathrm{RA}^{+}}$(TEMRA) peripheral $\mathrm{CD}^{+}$or $\mathrm{CD}^{+} \mathrm{T}$ lymphocytes (4). Other laboratory findings include elevated serum levels of interleukin (IL)-10, vitamin B12, and soluble Fas ligand. ALPS is genetically heterogeneous, and both somatic and germline mutations have been identified in the TNFRSF6 (encoding FAS and also referred to as CD95 or Apo-1), FAS-LG (Fas ligand), and CASP10 genes (5-8). Immunosuppressive treatments, including steroids or lymphotoxic drugs, are usually efficient to control the disease. Importantly, hyperactivation of the mTOR pathway has been shown to promote the lymphoproliferation in ALPS-FAS patients (9). This seminal study on ALPS pathophysiology prompted the clinicians to use mTOR-inhibitorbased treatments in ALPS patients, which showed very good efficacy (10). Mutations in TNFRSF6 impair the formation of the death-inducing-signaling complex or the Fas/Fas ligand interaction (either by modifying Fas' structure or precluding its membrane expression) (11). Thus, a defect in this pathway leads to the expansion of $\mathrm{T}$ and $\mathrm{B}$ lymphocytes including self-antigenspecific populations and thus autoimmunity as a consequence of cell death resistance. Indeed, a well-designed experiment, taking advantage of a loss-of-start mutation accompanied with somatic loss of heterozygosity, evidenced a disturbed B-lymphocytes selection in ALPS-FAS patients (12). Moreover, the role of the B-cell subset in the pathophysiology is also underlined by the increased risk of lymphoma, mostly of B-cell origin (13-15). However, there is no correlation between the magnitude of the apoptosis defect in vitro and the severity of the disease in vivo. Moreover, some FAS mutations may not be sufficient to trigger the disease, since asymptomatic carriers of germline FAS mutations have been described (i.e., partial clinical penetrance). The magnitude of the functional T cell defect is similar in asymptomatic carriers and symptomatic patients. Furthermore, ALPS is the only autoimmune syndrome in which a germline mutation on one TNFRSF6 allele (72\%) and a somatic mutation on the other $(0.5 \%)$ leads to disease onset; this explains the observed clinical differences between carriers of heterozygous germline mutations. This accumulation of genetic events provides the mutated cells with a selective advantage and is thus analogous to Knudson's two-hit hypothesis of carcinogenesis (16). This finding shows that somatic mutations can lead to autoimmune disease and might explain the incomplete penetrance observed in familial autoimmunity. Lastly, this finding implies the existence of factors that modify the onset of ALPS.

Along with programmed cell death, self-tolerance is also achieved via active suppression of lymphocyte proliferation by regulatory $\mathrm{T}$ cells (Tregs). The latter are defined phenotypically by the expression of CD4, FOXP3, and CD25 (the IL-2 receptor $\alpha$ chain) and the absence of CD127 (the IL-7 receptor) (17). Tregs have a key role in the prevention of autoimmunity and inflammation, as evidenced by the early-onset, severe autoimmune diseases

TABLE 1 | Clinical and genetic features of 16 ALPS patients

\begin{tabular}{|c|c|c|c|c|c|c|c|c|c|}
\hline Patients & $\begin{array}{l}\text { Range age } \\
\text { (years) }\end{array}$ & $\begin{array}{l}\text { Germline FAS } \\
\text { mutation }\end{array}$ & $\begin{array}{l}\text { Somatic FAS } \\
\text { mutation }\end{array}$ & Treatment & $\begin{array}{c}\text { In vitro } \\
\text { apoptosis defect }\end{array}$ & IL-10 (pg/ml) & $\begin{array}{l}\text { FASL } \\
\text { (ng/ml) }\end{array}$ & $\begin{array}{l}\text { sCD25 } \\
\text { (ng/ml) }\end{array}$ & DN/TCRab(\%) \\
\hline$P 1^{a}$ & $2-10$ & & Ex9: R250G & YES + C & NO & 13 & 0.5 & NT & 2 \\
\hline P2 & $2-10$ & Ex9: D269fsX277 & & YES & / & 110 & 4.3 & NT & 9 \\
\hline P3 & $2-10$ & Ex8:DelP217 X 220 & & YES & YES & 51 & 0.3 & $>11$ & 9 \\
\hline P4 & $2-10$ & Ex8:DelP217 X 220 & & NO & / & 60 & 1.46 & NT & 21 \\
\hline P5 & $12-19$ & Ex 7: Q196X & & YES & YES & 90 & 1 & $>11$ & 9 \\
\hline P6 & $12-19$ & Ex9: D265G & & YES + C & YES & 58 & 1 & NT & 7 \\
\hline P7 & $12-19$ & Ex7: E194fsx214 & & $\mathrm{NO}$ & YES & 31 & 1.3 & NT & 14 \\
\hline P8 & $12-19$ & Ex9: S230fs X241 & & YES & YES & $<1$ & 0.4 & $>11$ & 4 \\
\hline Pga & $12-19$ & & Ex 8 duplication & NO & NO & 63 & 1.07 & $>11$ & 29 \\
\hline $\mathrm{P} 10^{\mathrm{a}}$ & $12-19$ & & Ex8:Del P217 X 220 & NO & NO & 101 & 1.2 & NT & 16 \\
\hline P11 & $20-29$ & Ex 9: G253D & & YES & YES & 20 & 1.1 & 9.3 & 14 \\
\hline $\mathrm{P} 12^{\mathrm{a}}$ & $20-29$ & & Ex 8: del P217 fs X220 & NO & NO & 73 & 1.6 & NT & 10 \\
\hline $\mathrm{P} 13^{\mathrm{a}}$ & $20-29$ & & Ex8: del- P217fs X220 & YES & NO & 203 & 4 & NT & 44 \\
\hline $\mathrm{P} 14^{\mathrm{a}}$ & $20-29$ & Ex 4: DelC135 & $\mathrm{IOH}$ & YES & NO & 38 & 0.74 & NT & 20 \\
\hline P15 & $>30$ & & Ex9: D269 fsX 279 & YES & YES & 30 & 2.23 & $>11$ & 19 \\
\hline P16 & $>30$ & & Ex8:Del P217 X 220 & NO & YES & 1 & 0.34 & NT & 21 \\
\hline
\end{tabular}

The patients' respective FAS mutations are indicated.

aDenotes somatic mutations.

Normative values are $<20 \mathrm{pg} / \mathrm{ml}$ for IL-10, $<0.2 \mathrm{ng} / \mathrm{ml}$ for FAS ligand, and $<3 \%$ for the proportion of DN T lymphocytes.

In CTs, the serum level of SCD25 was around $2 \mathrm{ng} / \mathrm{ml}$.

NT, not tested; $1 \mathrm{OH}$, loss of heterozygote; C, corticoid. 
caused by defects in Treg function or development $(18,19)$. Indeed, mutations of the human FOXP3 gene (encoding the forkhead box $\mathrm{P} 3$ transcription factor) result in a fatal, systemic, autoimmune and inflammatory disease linked to the syndrome called immune dysregulation, polyendocrinopathy, enteropathy, X-linked (IPEX).
CD25 deficiency also results in severe autoimmunity and allergy and is phenotypically indistinguishable from IPEX (20). IL-2 secretion by activated, conventional effector T cells (Tconvs) is critical for the development, survival, and function of FOXP3 ${ }^{+}$ natural Tregs (nTregs) $(21,22)$. More recently, it has been

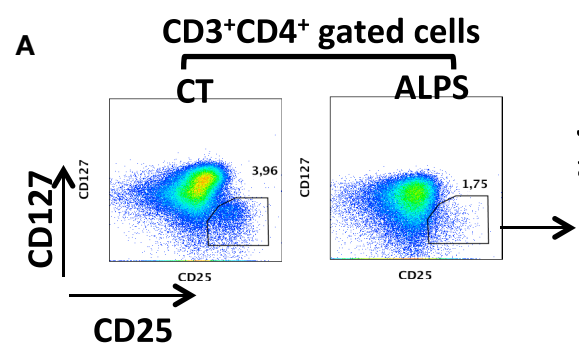

B
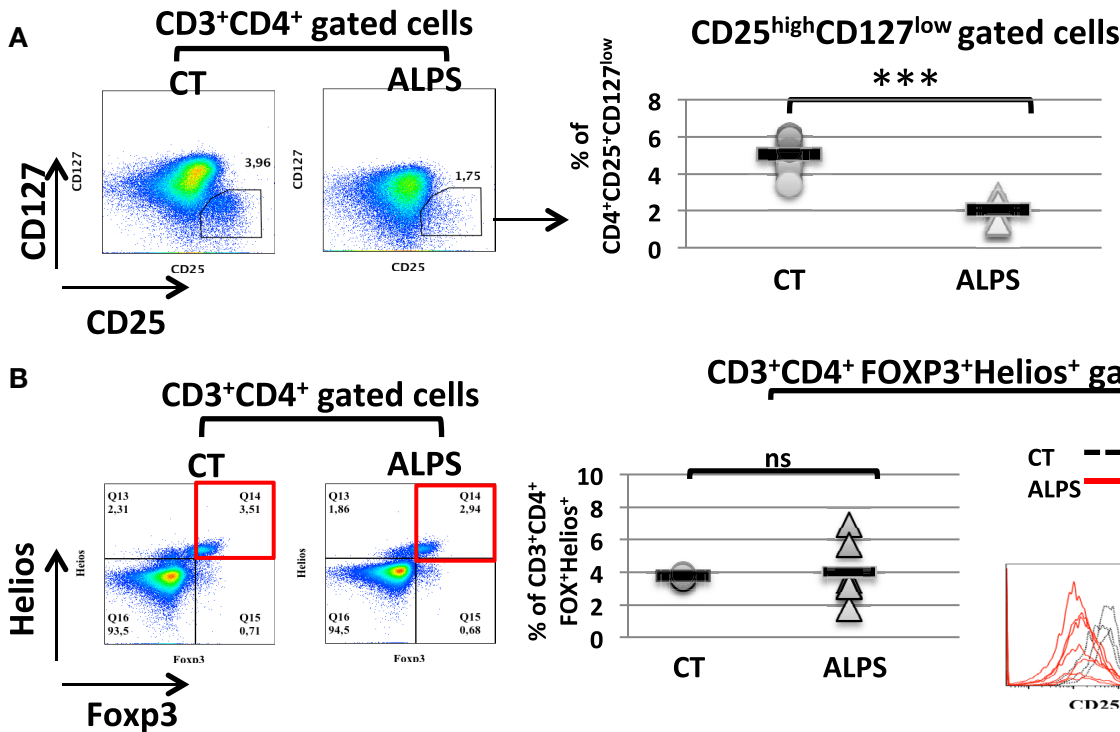

C $\mathrm{CD}^{+} \mathrm{CD}^{+}$gated cells
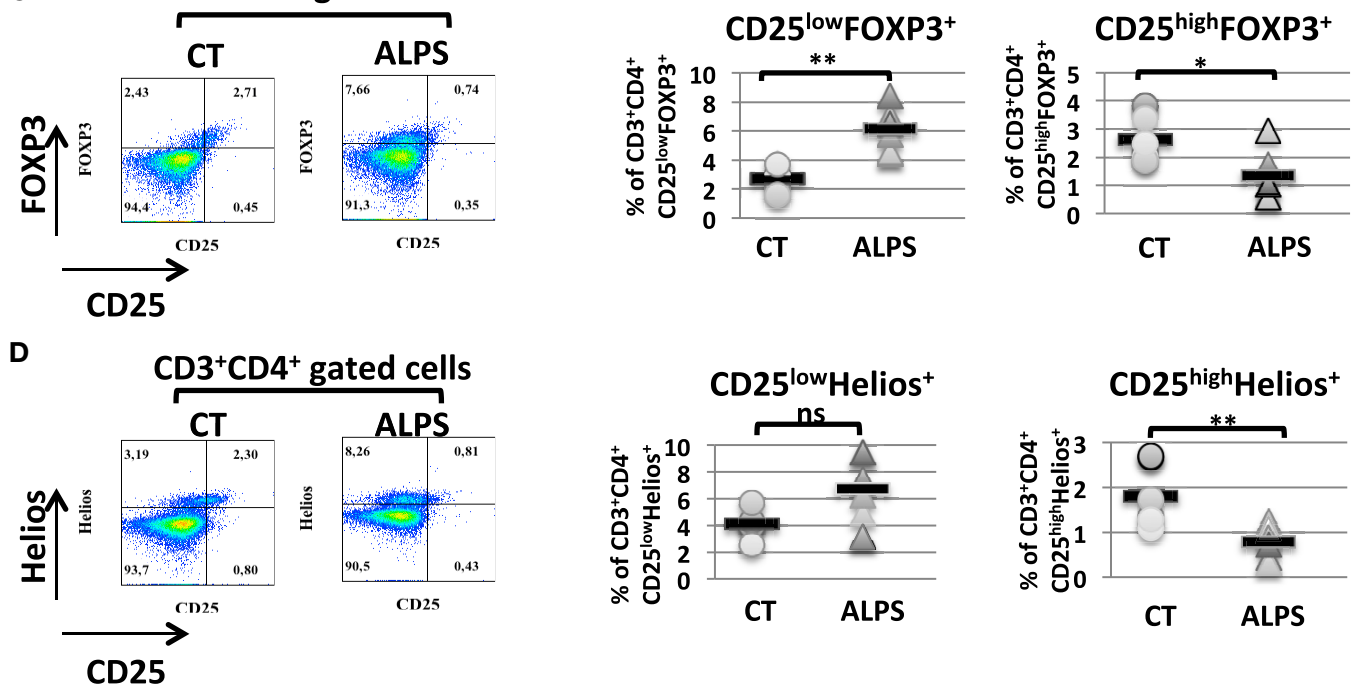

E
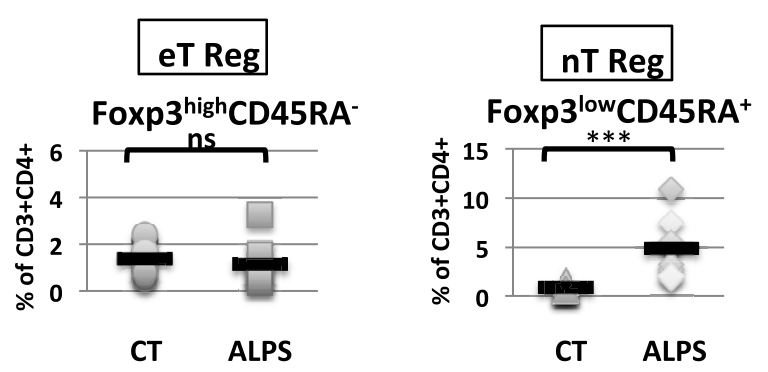

FIGURE 1 | Continued 
FIGURE 1 | Phenotypic characteristics of regulatory T cells (Tregs) in autoimmune lymphoproliferative syndrome (ALPS) patients. Stained CD3+CD4+-gated T lymphocytes isolated from seven healthy controls (CTs) and seven ALPS patients (ALPS) are shown. (A) shows the mean \pm SD (range) percentage of $\mathrm{CD}^{+}{ }^{+} \mathrm{CD} 127^{-} \mathrm{CD}^{+}{ }^{+} \mathrm{CD} 4{ }^{+}$gated cells: $2.1 \pm 0.2 \%(1.30-3.06 \%)$ in ALPS patients and $5.1 \pm 0.2 \%(3.45-6.07 \%)$ in CTs $\left(^{\star * \star} p<0.0001\right)$. (B) shows the mean \pm SD (range) percentage of the FOXP3+Helios+ ${ }^{+}$T cells subpopulation: $4 \pm 1.7 \%(1.79-6.89 \%)$ in ALPS patients and $3.77 \pm 0.1 \%(3.64-4 \%)$ in CTs. The histograms represent the staining of CD25, CD45RA, and CD127 on FOXP3 ${ }^{+}$Helios $^{+} \mathrm{CD}^{+}{ }^{+} \mathrm{CD} 4^{+}$-gated cells. For CTs (dashed black lines), the mean \pm SD fluorescence intensities were 5,536 \pm 1,275 (CD25), 1,518 \pm 519 (CD45RA), and $280 \pm 46$ (CD127). For ALPS patients (solid red lines), the mean \pm SD fluorescence intensities were 2,388 \pm 658 (CD25), 7,171 $\pm 3,507$ (CD45RA), and $197 \pm 81$ (CD127). In (C), the mean \pm SD (range) percentage of CD25 high FOXP3 ${ }^{+}$T cells subpopulation from gated $\mathrm{CD}^{+} \mathrm{CD}^{+} \mathrm{T}$ cells was $1.33 \pm 0.8 \%(0.56-2.94 \%)$ in ALPS patients and $2.75 \pm 0.75 \%(1.9-3.88 \%)$ in $\mathrm{CTs}$. The percentage of CD25low FOXP3 ${ }^{+}$ T cells is $6.1 \pm 0.62 \%(4.41-8.42)$ in ALPS patients and $2.5 \pm 0.38 \%(1.6-3.71)$ in CT $\left({ }^{\star *} p=0.0022,{ }^{*} p=0.026\right)$. In (D), the mean \pm SD (range) percentage of CD25 $^{\text {high Helios }}{ }^{+}$T cells subpopulation was $0.78 \pm 0.33 \%(0.32-1.25 \%)$ in ALPS patients and $2 \pm 0.6 \%$ (1.3-2.7\%) in CTs. The percentage of CD25 low Helios ${ }^{+}$ T cells was $6.7 \pm 2.3 \%$ (3.14-9.48\%) in ALPS patients and $4.1 \pm 1 \%(2.54-5.7 \%)$ in CTs $\left({ }^{\star \star} p=0.0043\right.$, ns: not significant). In (E), the percentages of

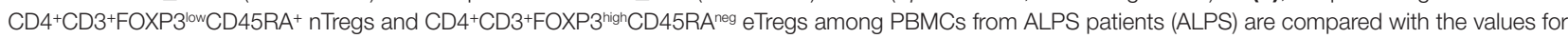
CTs (CONTROL). The error bars correspond to the mean \pm SD for duplicates. The mean \pm SD (range) percentage of eTregs was $1.36 \pm 0.17 \%(0.81-2.39 \%)$ in CTs $(n=12)$ and $1.19 \pm 0.3 \%(0.41-3.25 \%)$ in ALPS patients $(n=9)$. The mean \pm SD (range) percentage of natural Tregs was $0.87 \pm 0.12 \%(0.46-1.64 \%)$ in CTs $(n=12)$ and $4.9 \pm 0.97 \%(1.83-10.90 \%)$ in ALPS patients $(n=9)$. Statistical analyses were performed using a non-parametric Mann-Whitney $U$-test $\left({ }^{\star \star \star} p<0.0001\right)$. ns: not significant.
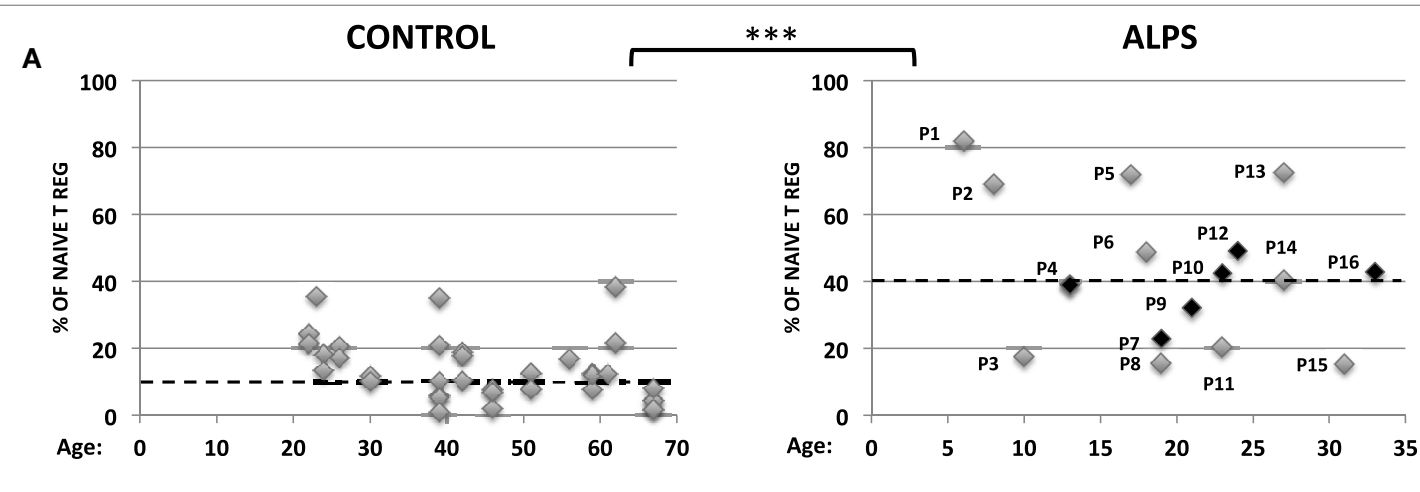

B
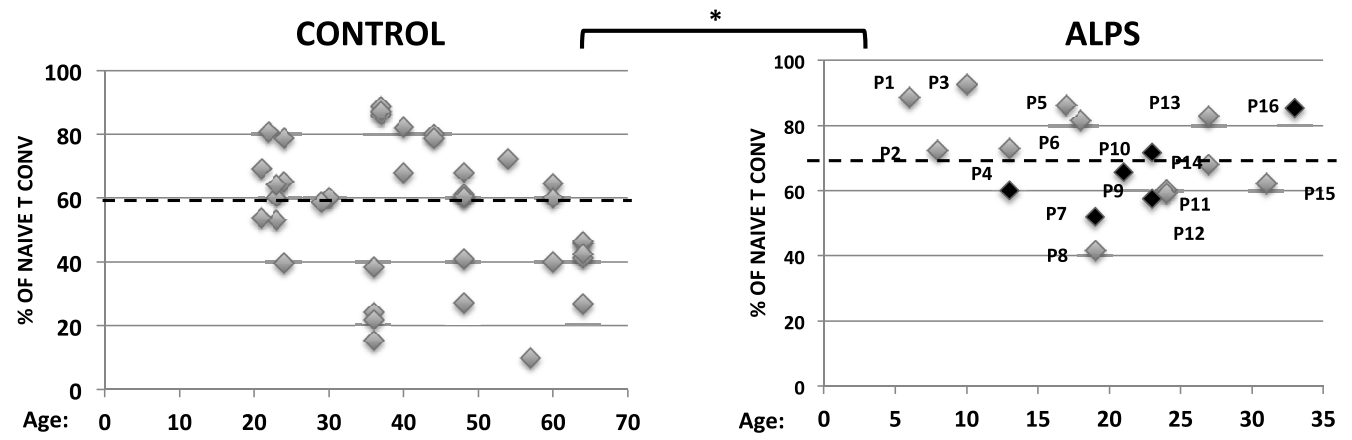

FIGURE 2 | Proportions of naïve regulatory T cells (Tregs) and naïve conventional effector T cell (Tconvs) in autoimmune lymphoproliferative syndrome (ALPS) patients. Percentages of $\mathrm{CD} 4{ }^{+} \mathrm{CD} 25^{+} \mathrm{CD} 127-\mathrm{CD} 45 \mathrm{RA}{ }^{+}$naïve Tregs (A) and CD4+CD25-CD127 ${ }^{+} \mathrm{CD} 45 \mathrm{RA}+$ naïve Tconvs (B) among PBMCs from 16 ALPS patients (right-hand panels) and healthy controls (CTs) (left-hand panels). The year of birth is indicated. For ALPS patients, the year of onset ranged from 2009 to 2014. Patients $(P)$ not having been treated at the time of the assay are indicated in black. The hatched line represents the mean percentage of naiive $T$ cell subpopulations. In panel A, the mean \pm SD (range) percentage of naïve Treg was $14.7 \pm 1.6 \%(2-38.3 \%)$ for CTs $(n=25)$ and $35.3 \pm 4.5 \%(15-82 \%)$ for ALPS patients $(n=16)$. In panel B, the mean \pm SD (range) percentage of naïve Tconvs was $56.5 \pm 3.3 \%(10-88.8 \%)$ for CTs $(n=35)$ and $70 \pm 3.3 \%(41-92.6 \%)$ for ALPS patients $(n=16)$. Statistical analyses were performed using a non-parametric Mann-Whitney U-test $\left({ }^{\star \star *} p<0.0001 ;{ }^{*} p=0.0205\right)$.

suggested that the expression of Helios (an Ikaros family transcription factor that enhances FOXP3 expression by binding to the FOXP3 promoter (23) and represses the IL-2 gene promoter (24)) can be used to discriminate between (i) nTregs that differentiate in the thymus and (ii) induced Tregs (iTregs) or effector Treg (eTregs) that differentiate in the peripheral tissues following exposure to antigen (25). However, it has also been shown that the Helios ${ }^{+}$ and Helios ${ }^{-}$nTregs have similar levels of suppressor activity and FOXP3 expression-suggesting that a lack of Helios expression is not a perfect marker of human iTregs (26).

Regulatory $\mathrm{T}$ cells suppress not only autoimmune responses but also other aberrant or excessive immune responses to nonself-antigens. There is now a growing body of evidence to suggest that Tregs can control almost all physiological or pathological 
A

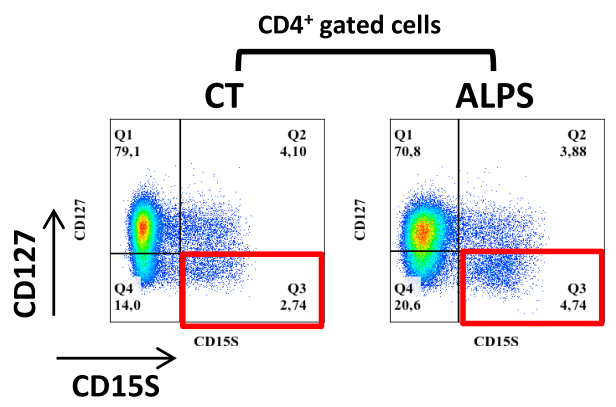

B

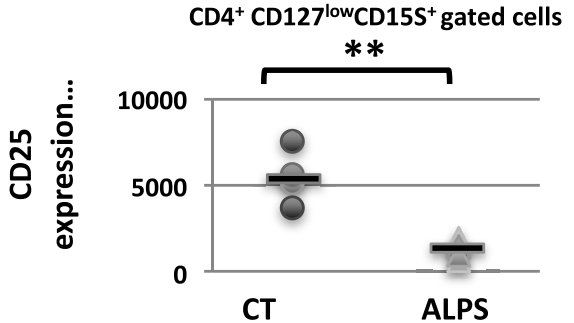

$\mathrm{CD}^{+}$CD127 ${ }^{\text {low }} \mathrm{CD} 15 S^{+}$gated cells

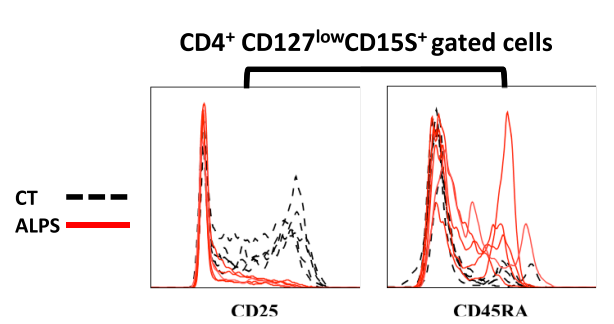

$\mathrm{CD}^{+}$CD127 ${ }^{\text {low }} \mathrm{CD} 15 \mathrm{~S}^{+}$gated cells

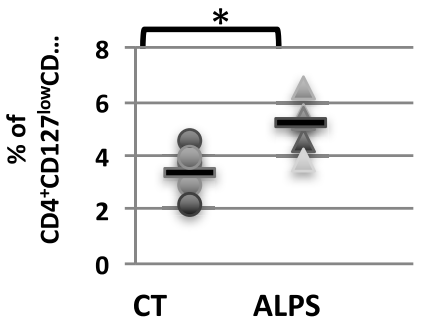

C
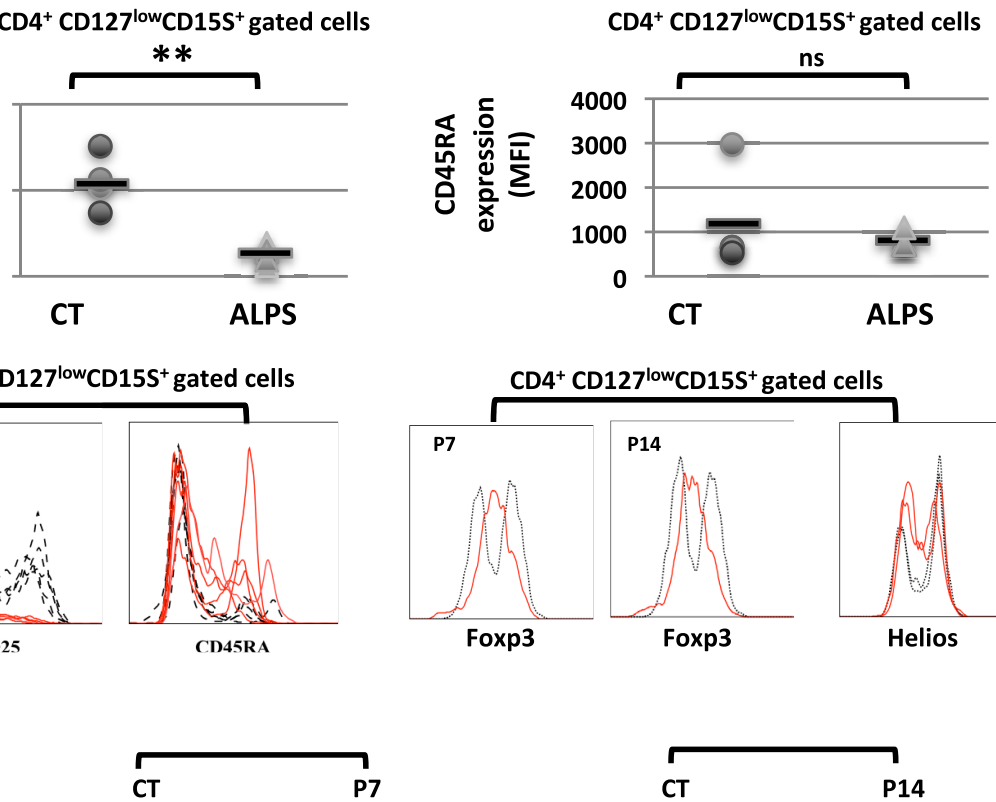

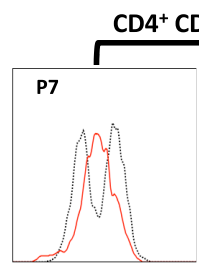

Foxp3

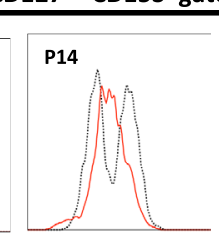

Foxp3

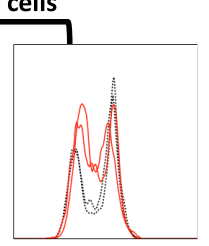

Helios
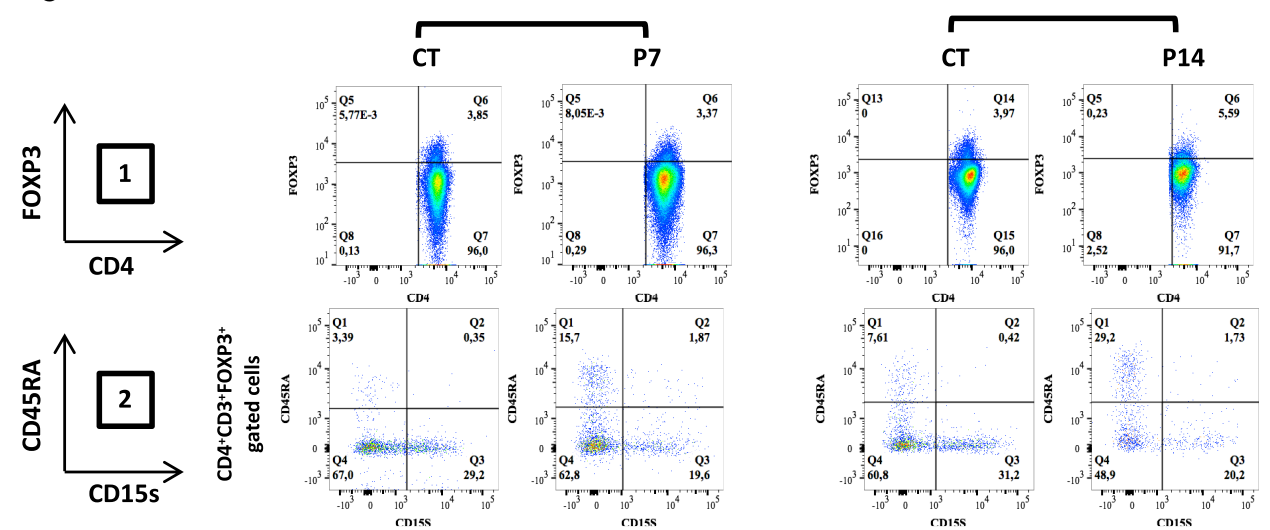

FIGURE 3 | Proportion and phenotype of CD127/ow $\mathrm{CD} 15 \mathrm{~s}^{+}$regulatory T cell (Treg) subpopulations in autoimmune lymphoproliferative syndrome (ALPS) patients. (A) $\mathrm{CD}^{+} \mathrm{CD}^{+}$-gated T lymphocytes isolated from four healthy controls (CTs) or five ALPS patients (ALPS) were stained for CD15S and CD127. The mean \pm SD (range) percentage of $\mathrm{CD} 127^{\mathrm{low}} \mathrm{CD} 15 \mathrm{~s}^{+} \mathrm{T}$ cells subpopulation was $5.1 \pm 0.4 \%$ (3.75-6.51\%) in ALPS patients and $3.3 \pm 0.4 \%(2.01-4.4 \%)$ in CTs is shown.

(B) $C D 4{ }^{+} C D 127^{\text {low }} \mathrm{CD} 15 \mathrm{~s}^{+}$-gated T cell subpopulations were stained for CD25, CD45RA, FOXP3, and Helios. The staining of FOXP3 and Helios was shown for two

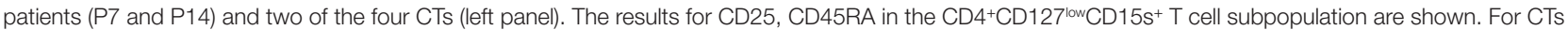
(dashed black lines), the mean \pm SD fluorescence intensities were 6,011 $\pm 1,950$ (CD25) and 1,225 $\pm 1,048$ (CD45RA). For ALPS patients (solid red lines), the mean \pm SD fluorescence intensities were 1,299 \pm 491 (CD25) and $761 \pm 164$ (CD45RA). $\left({ }^{\star *} p=0.0029,{ }^{*} p=0.0124\right.$, ns: not significant). (C) The expression of CD4 and FOXP3 was shown on $\mathrm{CD}^{+} \mathrm{CD} 4^{+}$-gated cells for two CTs, and two patients (P7 and P14) are shown in panel 1. The percentage of CD15s ${ }^{+} \mathrm{CD} 45 \mathrm{RA}{ }^{\text {neg }}$ cells on $\mathrm{CD}^{+}{ }^{+} \mathrm{CD} 4^{+} \mathrm{FOXP3}^{+}$-gated cells is shown for two patients (P7 and P14) and two controls (CT) (panel 2). Statistical analyses were performed using a non-parametric Mann-Whitney U-test. 
responses of the adaptive immune system. Furthermore, several mechanisms of Treg-mediated suppression have been proposed; these include the secretion of immunosuppressive cytokines (IL-10 and TGF- $\beta$ ) and the cell-cell-contact-dependent suppression, functional modification, and killing of antigen-presenting cells (APCs). Alternatively, the absorption of cytokines by Tregs may deprive responder $\mathrm{T}$ cells of cytokines and thus induce apoptosis (27). The effectiveness of this suppression also depends on the sensitivity/resistance of Tconvs to the inhibitory effects of Tregs. We hypothesized that this key checkpoint for self-tolerance controls the lymphoproliferation and autoimmunity observed in ALPS-Fas. Hence, in order to check whether one or more functional defects in the Treg and/or Tconv populations might be involved in ALPS, we investigated the Tregs' phenotype and function in ALPS patients with a Fas defect.

\section{PATIENTS AND METHODS}

\section{Cell Isolation}

Purified PBMCs from adult CTs (French Blood Transfusion Service, Paris, France) and patients with ALPS were prepared by density gradient centrifugation on Lymphoprep (Abcyss SA). The donor age range was 21-64 years for CTs and 6-33 years for patients with ALPS. Tconvs, Tregs, and dendritic cells (DCs) were sorted using flow cytometry.

\section{Antibodies and Reagents}

Anti-CD14 conjugated to violet blue was purchased from Miltenyi Biotec (Bergisch Gladbach, Germany). FITC-anti-CD4, PE Cy5anti-CD11c, PE-anti-CD25, BV650-anti-CD25, APC-antiCD45RA, BV711-anti-CD15s, PE-anti-CD45RA, PC5-anti-CD28, and $\mathrm{PE}$ anti-CTLA-4 were obtained from BD Biosciences (Mountain View, CA, USA). PE CY7 anti-CD127, BV421-anti CCR7, PE-anti-CD59, and BV510-anti-CD27 were purchased from Sony Biotechnology (San Jose, CA, USA); PE-FOXP3, APC-FOXP3, and eF450-Helios were supplied by eBiosciences (San Diego, CA, USA); PC5 anti-ICOS, APC-anti-PD1, BV421anti-CD39, APC-anti-GITR, and BV421-anti LAG3 were purchased from Biolegend (San Diego, CA, USA); and staphylococcal enterotoxin E (SEE) was purchased from Toxin Technology Inc.; and CellTrace carboxyfluorescein succinimidyl ester (CFSE) was purchased from Molecular Probes (Eugene, OR, USA). The antiCD3 (OKT3) used for some proliferation assays was purchased from Biolegend (San Diego, CA, USA).

\section{Purification of T Cells From PBMCs and Co-Culture With Sorted DCs}

PBMCs were incubated for $30 \mathrm{~min}$ at $4^{\circ} \mathrm{C}$ with specific, labeled monoclonal antibodies, washed, and then sorted using an ARIA II cytometer (BD Biosciences). Naïve Tconvs were defined as $\mathrm{CD}^{+} \mathrm{CD} 25^{-} \mathrm{CD} 127^{+} \mathrm{CD} 45 \mathrm{RA}^{+} \mathrm{T}$ cells, Tregs were defined as $\mathrm{CD} 4^{+} \mathrm{CD} 25^{\text {high }} \mathrm{CD} 127^{\text {low }} \mathrm{T}$ cells, nTregs were defined as $\mathrm{CD}^{+} \mathrm{CD} 25^{\text {high }} \mathrm{CD} 127^{\text {low }} \mathrm{CD} 45 \mathrm{RA}^{+} \mathrm{T}$ cells, and memory Tregs were defined as $\mathrm{CD} 4{ }^{+} \mathrm{CD} 25^{\text {high }} \mathrm{CD} 127^{\text {low }} \mathrm{CD} 45 \mathrm{RA}^{-} \mathrm{T}$ cells. DCs were defined as $\mathrm{CD} 11 \mathrm{c}^{+} \mathrm{CD} 4^{\text {low }} \mathrm{CD} 14^{-}$cells and monocytes were defined as $\mathrm{CD} 11 \mathrm{c}^{+} \mathrm{CD} 4^{\text {low }} \mathrm{CD} 14^{+}$cells. After cell sorting, naïve Tconvs were washed and stained with CellTrace CFSE (to determine specific naïve Tconv proliferation). Next, the cells were washed and incubated with DCs (Tconv:sorted DC ratio of 1:0.4). Tregs were added, to give a Treg:naïve Tconv ratio of 1:0.2 or $1: 1$. SEE $(0.2 \mathrm{ng} / \mathrm{ml})$ was then added. The cell proliferation assay was performed with autologous and heterologous samples in Panserin medium (Dutscher, Brumath, France) supplemented with 5\% human AB serum in 96-well plates. After 5 days of culture, the percentage of proliferating cells was measured with a MACSquant system (Miltenyi), and the data were analyzed with FlowJo software. Results were expressed as the percentage of proliferating cells. In the presence of Tregs or the results are expressed in percentage of the inhibition of proliferation. To test the reproducibility of these experiments, cells from the various patients were tested against different CTs or against the same CT. Similar results were obtained under both conditions.

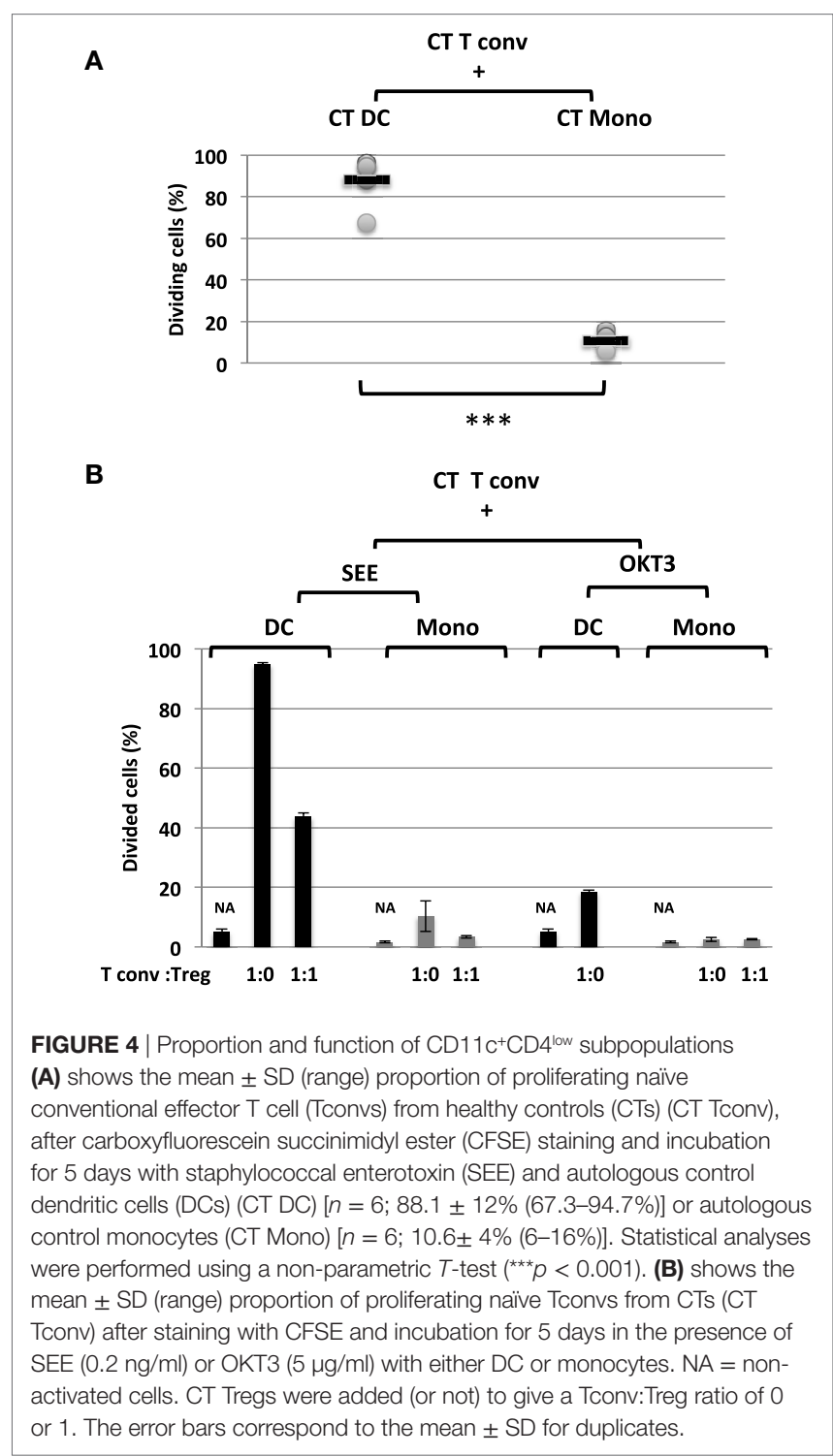


A FOXP3 staining/permeabilizing buffer set (eBiosciences) was used for the intracellular staining of FOXP3, Helios, and CTLA-4.

\section{Patients and Ethical Aspects}

We studied a cohort of 16 patients (summarized in Table 1) with typical manifestations of ALPS (adenopathy, lymphadenopathy, anemia, thrombopenia, and splenomegaly). The patients carried various heterozygous germline TNFRSF6 mutations affecting the intracellular domain of the protein and were all registered in the French national primary immunodeficiency database (CEREDIH, Paris, France) (16). As indicated in Table 1, some patients were being treated with immunosuppressive treatments. Written informed consent (parental consent, in case of

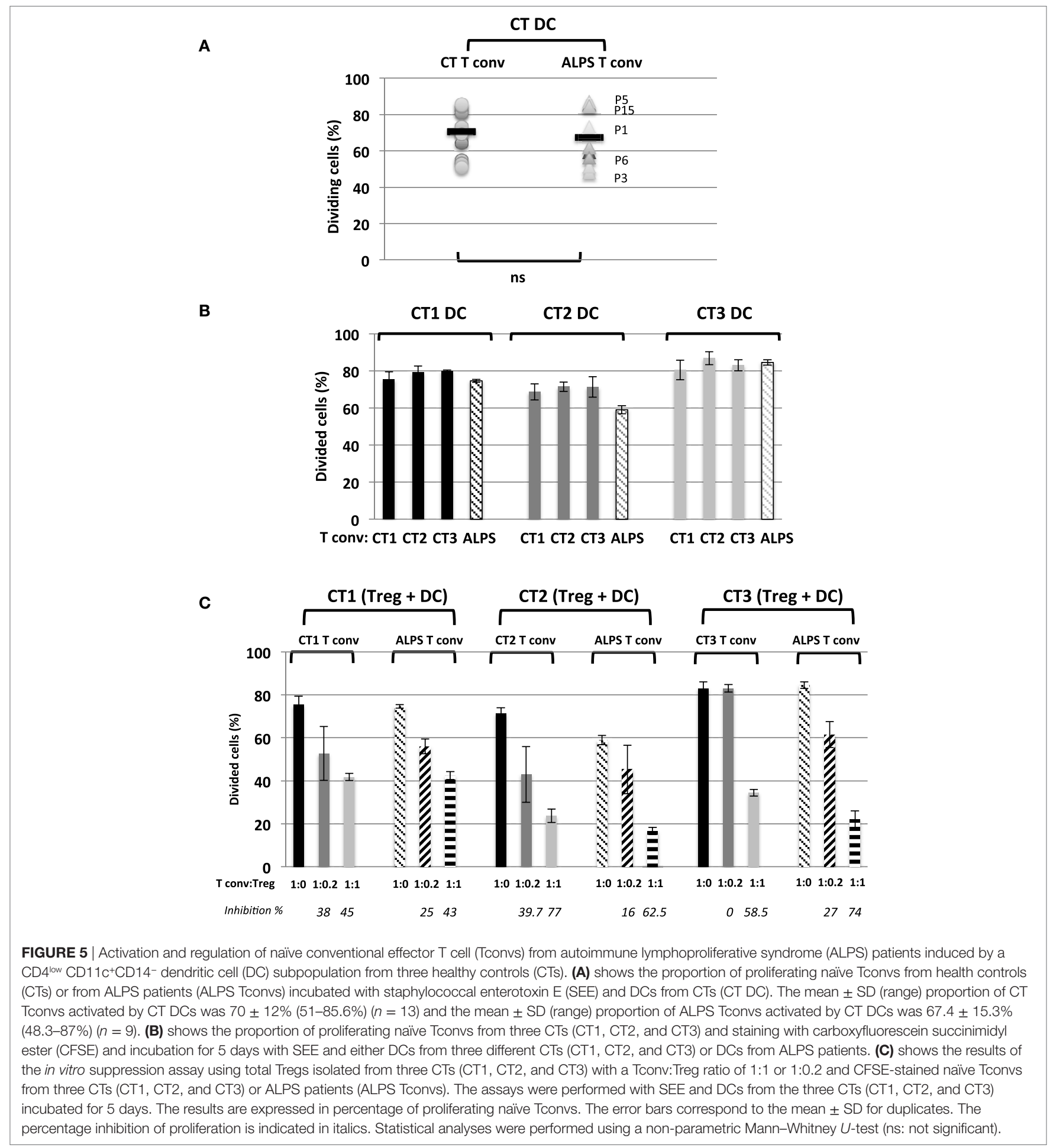


minors) was obtained from all participants of the study. The study protocols conform to the 1975 Declaration of Helsinki and were approved by the comité de protection des personnes Ile de France II and the French advisory committee on data processing in medical research.

\section{Statistical Analysis}

All analyses were performed using GraphPad Prism software (version 6, GraphPad Software, Inc., La Jolla, CA, USA). A nonparametric Mann-Whitney $U$-test was used to compare the data for the various populations from the patients and controls.
A

CT T conv + CT DC

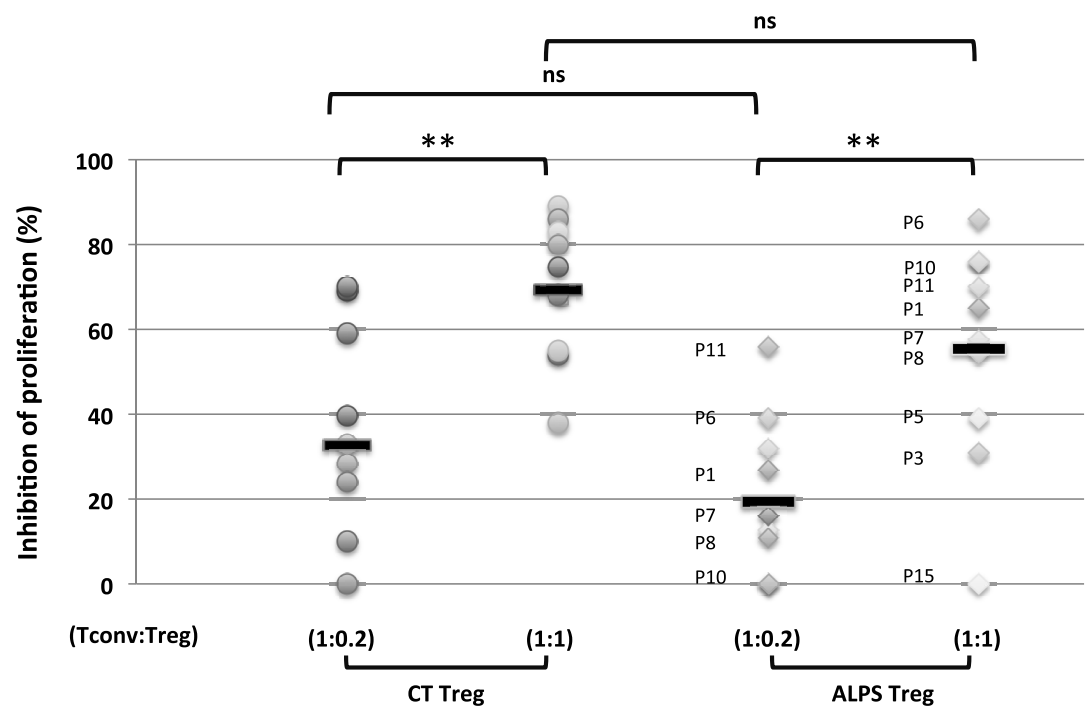

B

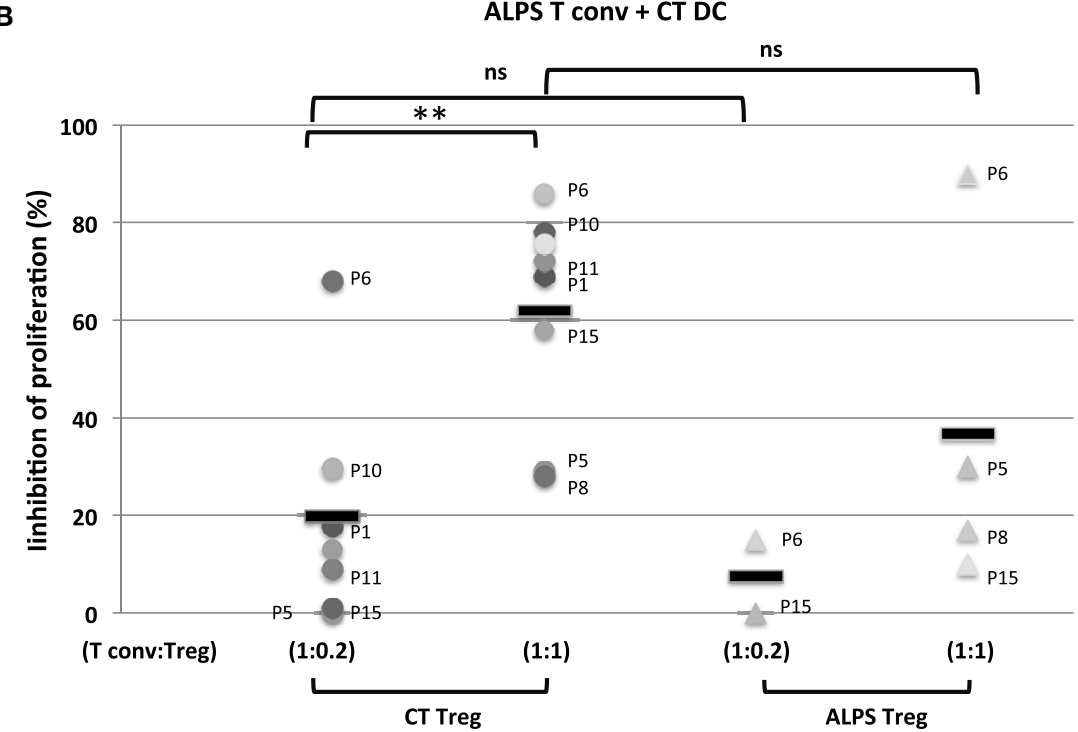

FIGURE 6 | Functional characteristics of regulatory T cells (Tregs) and conventional effector T cell (Tconvs) from autoimmune lymphoproliferative syndrome (ALPS) patients. The figure shows the results of an in vitro suppression assay using total Tregs isolated from healthy controls (CTs) (CT Treg) and ALPS patients (ALPS Treg) with a Tconv:Treg ratio of 1:1 or 1:0.2 and carboxyfluorescein succinimidyl ester (CFSE)-stained naïve Tconvs from CTs [CT Tconv: in (A)] or ALPS patients [ALPS Tconv, in (B)]. The assays were performed with staphylococcal enterotoxin E (SEE) and dendritic cells (DCs) from CTs (CT DC) for 5 days. The results are expressed in percentage of inhibition of proliferating cells. Statistical analyses were performed using a non-parametric $T$-test $\left({ }^{\star \star *} p<0.001,{ }^{* *} p<0.005,{ }^{*} p<0.05\right.$, ns: not significant). The error bars correspond to the mean \pm SD for duplicates. Panel (A) shows the mean (range) percentage of inhibition of CT Tconv proliferation by the CT Tregs (69.4 $\pm 16.4 \%)(38-89 \%)$ for a Tconv:CT Treg ratio of 1:1 $(n=10) ; 32.8 \pm 21.6(0-69 \%)$ for a CT Tconv:CT Treg ratio of 1:0.2 $(n=10)$ and by the ALPS Tregs [55.5 $\pm 26 \%(0-86 \%)]$ for a CT Tconv:ALPS Treg ratio of 1:1 $(n=10) ; 19.4 \pm 18.8(0-56 \%)$ for a CT Tconv:ALPS Treg ratio of 1:0.2 ( $n=10)$. Panel (B) shows the mean (range) percentage of inhibition of ALPS Tconv proliferation by CT Tregs [61.6 $\pm 21 \%(28-86 \%)]$ for a ALPS Tconv:CT Treg ratio of 1:1 $(n=9): 21.6 \pm 22 \%$ $(0-69 \%)$ for a ALPS Tconv:CT Treg ratio of 1:0.2 $(n=8)$ or by ALPS Tregs $(36.7 \pm 36 \%)(10-90 \%)$ for an ALPS Tconv:ALPS Treg ratio of 1:1 $(n=4) ; 7.4 \pm 10.6$ $(0-15 \%)$ for an ALPS Tconv:ALPS Treg ratio of 1:0.2 $(n=2)$. 


\section{RESULTS}

\section{Phenotypic Characteristics of Tregs in ALPS Patients}

We studied 16 ALPS patients (Table 1). By studying the CD25 and CD127 surface markers, we observed abnormally low percentages of the $\mathrm{CD} 25^{\text {high }} \mathrm{CD} 127^{\text {low }}$ Treg subsets in all tested ALPS-Fas patients, relative to CTs (Figure 1A). We then measured the combined intracellular expression of the transcription factors FOXP3 and Helios in $\mathrm{CD}^{+} \mathrm{CD}^{+}$-gated T cells, in order to estimate the proportion of Tregs. Although this proportion varied from one patient to another, there was no significant overall difference between patients and CTs. However, when assessing CD25, CD45RA, and CD127 as additional surface markers for Tregs, we observed an abnormally low CD25 expression, an abnormally high CD45RA expression, and a normal CD127 expression in the ALPS-FAS patients (Figure 1B). The low CD25 expression was observed in both $\mathrm{FOXP}^{+}$and $\mathrm{Helios}^{+}$populations (Figures 1C,D); this is an important observation, since the CD25 is conventionally used as a Treg marker (notably in combination with FOXP3 staining). Furthermore, we observed an abnormally high proportion of naïve Tregs (FOXP $3{ }^{\text {low }} \mathrm{CD}_{45 \mathrm{RA}^{+}}$) relative to eTregs $\left(\mathrm{FOXP} 3{ }^{\text {high }} \mathrm{CD} 45 \mathrm{RA}^{-}\right.$) in the ALPS patients (Figure 1E). This nTreg/eTreg imbalance was not correlated with age (Figure 2A). Similarly, we observed a slightly but significantly elevated proportion of the CD45RA ${ }^{+}$subset among $\mathrm{CD} 4^{+} \mathrm{CD} 25^{-} \mathrm{CD} 127^{+}$Tconvs (Figure 2B). We also investigated the expression of the Treg markers on activated, terminally differentiated and most strongly suppressive FOXP $3^{\text {high }}$ eTregs. The latter specifically express the CD15s marker (sialyl Lewis X) recently described in human blood by Miyara et al. (28). We observed a slightly higher proportion of $\mathrm{CD} 4^{+} \mathrm{CD} 127^{\text {low }} \mathrm{CD} 15 \mathrm{~s}^{+}$ cells (Figure 3A) in six out of six ALPS patients tested, relative to CTs. Again, we observed a low expression of the CD25 marker (Figure 3B) and an intermediate level of FOXP3 expression (Figure 3B). By contrast, the levels of Helios expression were very similar in ALPS patients and CTs (Figure 3B). We then analyzed the expression of the CD45RA and CD15s markers on the $\mathrm{CD}^{+} \mathrm{CD}^{+}{ }^{+} \mathrm{FOXP}_{3}{ }^{+}$population in $\mathrm{P} 7$ and $\mathrm{P} 14$ (Figure $3 \mathrm{C}$, panel 1). The proportion of the $\mathrm{CD}^{+} \mathrm{CD} 4{ }^{+} \mathrm{CD} 15 \mathrm{~s}^{+} \mathrm{CD} 45 \mathrm{RA}{ }^{\text {neg }}$ subpopulation was slightly decreased as compared to controls (Figure 3C, panel 2). Additional markers have been studied on $\mathrm{CD} 4^{+} \mathrm{CD} 127^{\text {low }} \mathrm{CD} 15 \mathrm{~s}^{+}$cells. We observed increased CCR7 and PD1 staining in three ALPS patients as compared to healthy controls (CTs) (Figure S1 in Supplementary Material). The other markers such as CTLA4 are not modified.

\section{Assessment of Tconv Sensitivity and Treg Function in Samples From ALPS Patients}

We next investigated the Tregs' suppressive function on $\mathrm{T}$ cell proliferation with regard to naïve $\mathrm{CD} 4^{+} \mathrm{CD} 45 \mathrm{RA}{ }^{+} \mathrm{CD} 25^{-} \mathrm{CD} 127^{+}$ Tconvs. The Tregs were stimulated for 5 days with SEE or antiCD3 antibody (OKT3) in the presence of CD11 ${ }^{+} \mathrm{CD} 4^{\text {low }}$ APCs. As previously described (29), we found that DCs (i) were more efficient as APCs than monocytes (Figure S2 in Supplementary Material) and (ii) sustained the proliferation of naïve Tconvs
(Figure 4A). Furthermore, stimulation with SEE was stronger than stimulator with OKT3 (Figure 4B). The proliferation of naïve Tconvs was of the same magnitude for ALPS patients and CTs (Figure 5A). Moreover, the naïve Tconvs from patients were stimulated to a similar extent by DCs from three independent CTs - thus emphasizing the assay's reproducibility (Figure 5B). Furthermore, we observed that the proliferation of Tconvs from these three independent CTs was inhibited to a similar extent, which thus ruled out donor-related variations (Figure 5C). Likewise, the proliferation of Tconvs from ALPS patients was fully inhibited by Tregs from three independent CTs (Figure 5C). Furthermore, Tregs from patients and CTs exhibited similar levels of suppressive activity under autologous and heterologous conditions (Figure 6). Similarly, the $\mathrm{CD} 44^{+} \mathrm{CD} 127^{\text {low }} \mathrm{CD} 25^{+} \mathrm{CD} 15 \mathrm{~s}^{+}$ Tregs isolated from two ALPS patients exhibited the same level of suppressive activity as Tregs from CTs (Figure 7).

\section{DISCUSSION}

The role of $\mathrm{FOXP}^{+}$Tregs is critical for controlling organ-specific autoimmunity, as demonstrated by the early onset of autoimmune enteropathy and endocrinopathy in IPEX patients and in mice harboring FOXP3 mutations. The extrinsic lymphocyte apoptosis mediated by the death receptor FAS also constitutes a tolerance checkpoint. Indeed, patients or mice harboring an FAS deficiency develop an early-onset lymphoproliferative disease with autoimmunity (essentially against platelets and red cells).

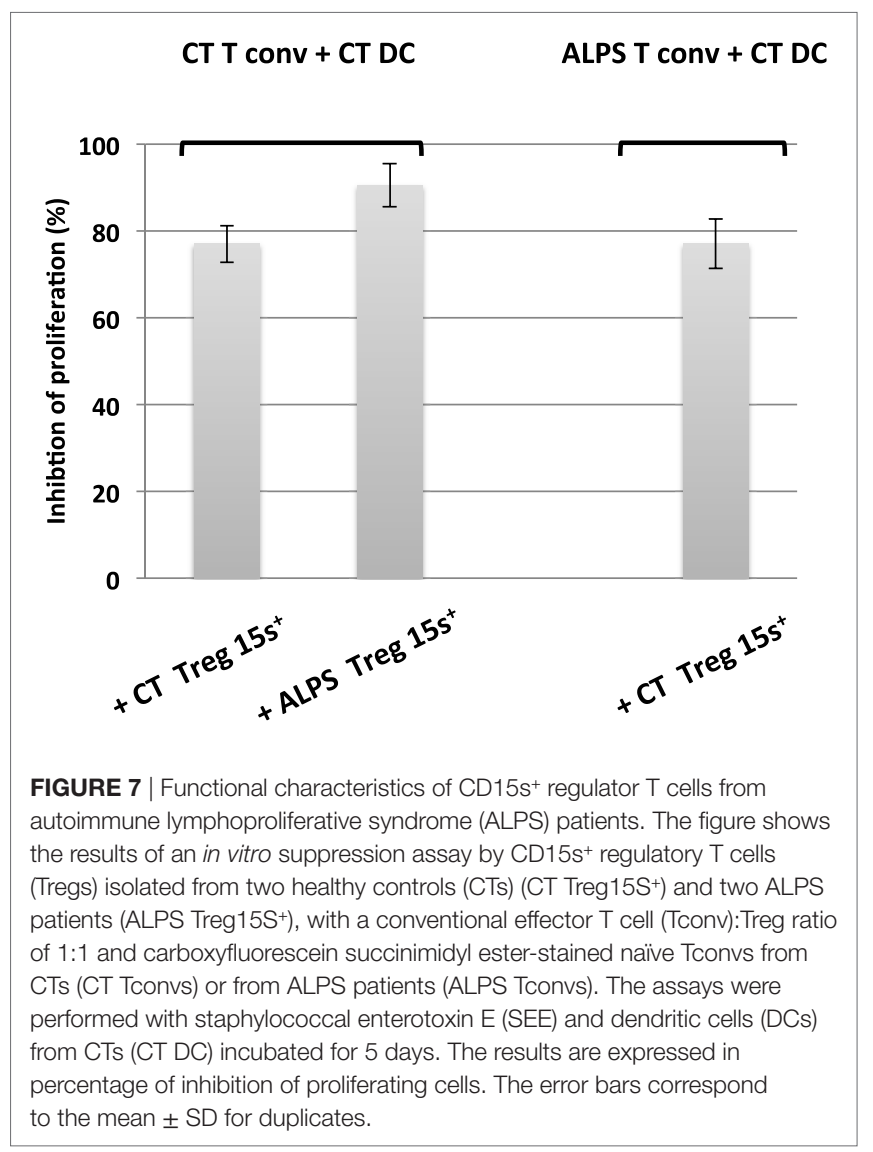


However, these two key tolerance checkpoints are unable to compensate for each other, since (i) FAS-mediated apoptosis does not control the autoimmunity that develops in FOXP3-deficient patients and (ii) Tregs do not control the autoimmunity observed in FAS-deficient patients. One can assume that in ALPS, some FAS-deficient target cells (i.e., gut epithelial cells and Langerhans beta cells in the pancreas) are more resistant to destruction by autoreactive $\mathrm{T}$ cells. This hypothesis is supported by the less severe autoimmune symptoms observed in FAS- and Tregdeficient mice (30). Moreover, Treg dysfunction might account for the active proliferation seen in ALPS-FAS patients, since impaired FAS-mediated cell death might not fully account for the generalized lymphoproliferation observed in patients and murine models. Hence, we decided to assess the Treg phenotype in ALPSFAS patients. We systematically observed low expression of the IL-2Ra chain (CD25), which was correlated with low proportions of $\mathrm{CD}^{+} \mathrm{CD}^{+} \mathrm{CD} 25^{\text {high }} \mathrm{FOXP} 3^{+}$Treg subsets. This result is consistent with the recently described role of IL-2R signaling in FOXP3 expression (31). Furthermore, we observed a low proportion of $\mathrm{CD} 3{ }^{+} \mathrm{CD} 4^{+} \mathrm{CD} 25^{\text {high }} \mathrm{CD} 127^{\text {low }}$ cells in ALPS patients. These Treg subpopulations displayed a naïve phenotype, as confirmed by the high proportion of $\mathrm{CD}^{+} \mathrm{CD}^{+} \mathrm{FOXP} 3^{\text {low }} \mathrm{CD} 45 \mathrm{RA}^{+}$cells. Our results indicate the possible presence of a memory/activated Treg unbalance in ALPS-FAS patients. This abnormal phenotype was not related to previous treatments or age, since it was also observed in untreated patients and in treated patients of various ages. In order to better define the Treg phenotype in ALPS patients, we examined the expression of CD15s - a recently described marker of activated, terminally differentiated, highly suppressive CD15s ${ }^{+}$CD45RA ${ }^{-}$eTregs (28). A slight elevation of the $\mathrm{CD} 4^{+} \mathrm{CD} 127^{\text {low }} \mathrm{CD} 15 \mathrm{~s}^{+}$subpopulation was observed in the ALPS-FAS patients, relative to CTs. However, this subpopulation also displayed a naïve phenotype and expressed normal levels of Helios, intermediate levels of FOXP3 and no CD25-thus defining a particular nTreg subpopulation $\left(\mathrm{CD} 15 \mathrm{~s}^{+} \mathrm{CD} 25\right.$ ${ }^{-} \mathrm{CD} 127^{\text {low }} \mathrm{CD} 45 \mathrm{RA}^{+} \mathrm{Helios}^{+} \mathrm{FOX}^{\text {med }}$ ) in ALPS-FAS patients. This subpopulation might originate from thymus-derived CD45RA ${ }^{+} \mathrm{FOXP}^{\text {low }}{ }^{2}$ elios ${ }^{+} \mathrm{CD}^{+}{ }^{+}$nTregs. Next, we investigated the functional activity of Tregs from ALPS patients by assessing the suppressive function of Tregs on Tconv cell proliferation. Overall, the conventional $\mathrm{CD} 25^{+} \mathrm{CD} 127^{\text {low }}$ Treg subpopulation and the $\mathrm{CD} 127^{\text {low }} \mathrm{CD} 15 \mathrm{~S}^{+} \mathrm{CD} 25^{\text {low }}$ Treg subpopulations had similar suppressive functions in samples derived from ALPS-FAS patients and CTs. Moreover, control Tregs $\left(\mathrm{CD} 25^{+} \mathrm{CD} 127^{\text {low }}\right.$ or CD $127^{\text {low }} \mathrm{CD} 15 \mathrm{~S}^{+}$) normally suppressed the ALPS-FAS patients' Tconvs proliferation. During the test, we have also observed that Treg proliferate (data not shown). This finding indicates that FAS-mediated cell death is not involved in the inhibition of Tconv proliferation by Tregs, or that a redundant pathway is involved. Taken as a whole, the results of our in vitro experiments evidenced normal Treg-suppressive function on $\mathrm{T}$ cell proliferation, even though the phenotype was abnormal (with a higher proportion of a CD25 $5^{\text {low }}$ Tregs) in the ALPS-FAS patients. The low expression of membrane $\mathrm{CD} 25$ by $\mathrm{CD} 4^{+} \mathrm{FOXP} 3^{+}$or $\mathrm{CD} 127^{\text {low }}$ or $\mathrm{CD} 15 \mathrm{~s}^{+}$populations might be related to the high plasma levels of the soluble form of CD25 (sCD25) detected in the six ALPS-FAS patients tested. This might result from an increased cleavage of CD25 by metalloproteinases, as has been observed in some lymphoproliferative disorders $(32,33)$. One cannot rule out the possibility that the high proportion of naïve Tregs reflects a reduced activation of the Tregs subset in vivo or results from the presence of $\mathrm{CD} 4^{+}$ terminally differentiated effector CD45RA ${ }^{+} \mathrm{T}$ cells (TEMRA), but the fact that these $\mathrm{CD} 4{ }^{+} \mathrm{FOXP} 3{ }^{\text {low }} \mathrm{CD} 45 \mathrm{RA}^{+}$cells also express CCR7 and CD27 argues against the possibility that these cells are TEMRAs. In addition, the normal suppressive function observed in vitro and the lack of clinical symptoms usually observed in Treg-deficient patients (i.e., autoimmune enteropathy and endocrinopathy) support the hypothesis whereby Treg functions, in particular inhibition of Tconvs proliferation, are unaffected in patients with FAS deficiency-despite the abnormal phenotype observed for circulating cells. However, Tregs from ALPS have been activated with control APCs (because insufficient numbers of ALPS-APCs retrieved upon cell sorting). We thus cannot exclude a putative in vivo defect of ALPS Tregs on ALPS-APCs regarding cytokine production (such as IL-10) or modification of some surface molecules on ALPS-APCs (such as CD86). Nevertheless, ALPS patients do not present with clinical features observed in "Tregopathies" (i.e., FOXP3 or CTLA-4 deficiencies) such as lymphocytic tissue infiltrations and organ-specific autoimmunity, in particular autoimmune enteropathy.

In conclusion, our present results show that abnormal proportions of Treg subsets are not necessarily pathogenic features in ALPS. Despite an apparently abnormal Treg phenotype in ALPS-FAS patients, a regulatory defect is unlikely to account for the active lymphoproliferation observed in this disease. Thus, it is still not clear why Tregs cannot control the lymphoproliferation of FAS-deficient $\mathrm{T}$ cells and thus cannot prevent autoimmune cytopenia in ALPS patients. Better knowledge of which $\mathrm{T}$ cells and/or which types of stimulation are most strongly controlled by the Treg-associated apoptosis pathway may help to identify more specific therapeutic targets in the future.

\section{ETHICS STATEMENT}

All patients are registered in the French national primary immunodeficiency database (CEREDIH, Paris, France). The study was performed in accordance with the precepts of the Declaration of Helsinki.

\section{AUTHOR CONTRIBUTIONS}

FM carried out all the functional experiments and wrote the paper. M-CS carried out the FACS experiments. OP has carried out the cell sorting on ARIA. CP, BN, and AF executed the followup of patients and manuscript discussion. AM-C did the manuscript discussion, and FR-L was responsible for the research project.

\section{FUNDING}

The authors would like to acknowledge the clinicians for providing the clinical information and the samples of the patients: F. Suarez and S. Blanche, We also thank S. Jacques for technical assistance. This work was funded by grants from the Institut National de la Santé et de la Recherche Médicale, the Fondation maladies rares, 
the European Research Council (ERC PIDIMMUN no. 249816 to AF), Agence Nationale de la Recherche (ANR-14-CE14-0026-01 "Lumugene" to FR-L), Institut National du Cancer (INCa 2014-1PL BIO-10-INSERM 5-1 to FR-L), Centre de Référence des Déficits Immunitaires Héréditaires (CEREDIH, to FR-L), Ligue National Contre le Cancer (To AM-C), and Fondation Maladies rares (to AM-C and to FR-L). This program has received a state subsidy managed by the National Research Agency under the "Investments for the Future" program bearing the reference ANR-10- IAHU-01 and IDEX Sorbonne Paris Cité (SPC/JFG/2013 - 031 to FR-L).

\section{SUPPLEMENTARY MATERIAL}

The Supplementary Material for this article can be found online at https://www.frontiersin.org/articles/10.3389/fimmu.2018.00718/ full\#supplementary-material.

\section{REFERENCES}

1. Fisher GH, Rosenberg FJ, Straus SE, Dale JK, Middleton LA, Lin AY, et al. Dominant interfering Fas gene mutations impair apoptosis in a human autoimmune lymphoproliferative syndrome. Cell (1995) 81(6):935-46. doi:10.1016/0092-8674(95)90013-6

2. Shah S, Wu E, Rao VK, Tarrant TK. Autoimmune lymphoproliferative syndrome: an update and review of the literature. Curr Allergy Asthma Rep (2014) 14(9):462. doi:10.1007/s11882-014-0462-4

3. Rieux-Laucat F, Magerus-Chatinet A. Autoimmune lymphoproliferative syndrome: a multifactorial disorder. Haematologica (2010) 95(11):1805-7. doi:10.3324/haematol.2010.030395

4. Rensing-Ehl A, Volkl S, Speckmann C, Lorenz MR, Ritter J, Janda A, et al. Abnormally differentiated $\mathrm{CD} 4+$ or $\mathrm{CD} 8+\mathrm{T}$ cells with phenotypic and genetic features of double negative $\mathrm{T}$ cells in human Fas deficiency. Blood (2014) 124(6):851-60. doi:10.1182/blood-2014-03-564286

5. Rieux-Laucat F, Le Deist F, Hivroz C, Roberts IA, Debatin KM, Fischer A, et al. Mutations in Fas associated with human lymphoproliferative syndrome and autoimmunity. Science (1995) 268(5215):1347-9. doi:10.1126/science.7539157

6. Wang J, Zheng L, Lobito A, Chan FK, Dale J, Sneller M, et al. Inherited human caspase 10 mutations underlie defective lymphocyte and dendritic cell apoptosis in autoimmune lymphoproliferative syndrome type II. Cell (1999) 98(1):47-58. doi:10.1016/S0092-8674(00)80605-4

7. Magerus-Chatinet A, Stolzenberg MC, Lanzarotti N, Neven B, Daussy C, Picard C, et al. Autoimmune lymphoproliferative syndrome caused by a homozygous null FAS ligand (FASLG) mutation. JAllergy Clin Immunol (2013) 131(2):486-90. doi:10.1016/j.jaci.2012.06.011

8. Bi LL, Pan G, Atkinson TP, Zheng L, Dale JK, Makris C, et al. Dominant inhibition of Fas ligand-mediated apoptosis due to a heterozygous mutation associated with autoimmune lymphoproliferative syndrome (ALPS) Type Ib. BMC Med Genet (2007) 8:41. doi:10.1186/1471-2350-8-41

9. Volkl S, Rensing-Ehl A, Allgauer A, Schreiner E, Lorenz MR, Rohr J, et al. Hyperactive mTOR pathway promotes lymphoproliferation and abnormal differentiation in autoimmune lymphoproliferative syndrome. Blood (2016) 128(2):227-38. doi:10.1182/blood-2015-11-685024

10. Klemann C, Esquivel M, Magerus-Chatinet A, Lorenz MR, Fuchs I, Neveux N, et al. Evolution of disease activity and biomarkers on and off rapamycin in 28 patients with autoimmune lymphoproliferative syndrome. Haematologica (2017) 102(2):e52-6. doi:10.3324/haematol.2016.153411

11. Magerus-Chatinet A, Stolzenberg MC, Loffredo MS, Neven B, Schaffner C, Ducrot N, et al. FAS-L, IL-10, and double-negative CD4- CD8- TCR alpha/beta+ $\mathrm{T}$ cells are reliable markers of autoimmune lymphoproliferative syndrome (ALPS) associated with FAS loss of function. Blood (2009) 113(13):3027-30. doi:10.1182/blood-2008-09-179630

12. Janda A, Schwarz K, van der Burg M, Vach W, Ijspeert H, Lorenz MR, et al. Disturbed B-lymphocyte selection in autoimmune lymphoproliferative syndrome. Blood (2016) 127(18):2193-202. doi:10.1182/blood-2015-04-642488
FIGURE S1 | Phenotypic characteristics of regulatory T cells (Tregs) in autoimmune lymphoproliferative syndrome (ALPS) patients. $C D 3^{+} C D 4^{+}$-gated T lymphocytes isolated from three healthy controls (CTS) (CT) or three ALPS patients (ALPS: P7, P8, and P15) were stained for CD25 and CD127 (A). Next, CD4+CD127-CD25+-gated T cell subpopulations were stained for CTLA4. In parallel, for two of these patients (ALPS: P7 and P15), CD3 ${ }^{+} C D 4^{+-}$ gated T lymphocytes isolated were also stained for CD15s and CD127. Next, CD4 ${ }^{+}$CD 127-CD15s ${ }^{+}$-gated T cell subpopulations were stained for CTLA-4 (B). The CD4+CD127-CD15s ${ }^{+}$-gated T cell subpopulations of three other patients were also stained for CCR7, GITR, ICOS, CD39, LAG3, CD59, PD1, CD27, and CD28 (C). The mean intensity of fluorescence was added for the control and the ALPS patients. Histograms are normalized to mode for panel (C)

FIGURE S2 | Different proportion of antigen-presenting cell (APC). The mean proportion of total $\mathrm{CD} 11 \mathrm{c}^{+} \mathrm{CD} 4^{\text {low }} \mathrm{APCs}$ (left panel) and the mean $\pm \mathrm{SD}$ (range) proportion of $\mathrm{CD} 11 \mathrm{C}^{+} \mathrm{CD} 4^{\text {low }} \mathrm{CD} 14^{+}$monocytes $[82.9 \pm 4 \%(75-89 \%) ; n=10$; middle panel] and CD11 $\mathrm{C}^{+} \mathrm{CD} 4^{\text {low }} \mathrm{CD} 14^{-}$- DCs $[15.8 \pm 5 \%(9-24 \%) ; n=11$; right panel] among PBMCs from CTs (CT).

13. Price S, Shaw PA, Seitz A, Joshi G, Davis J, Niemela JE, et al. Natural history of autoimmune lymphoproliferative syndrome associated with FAS gene mutations. Blood (2014) 123(13):1989-99. doi:10.1182/blood-2013-10-535393

14. Neven B, Magerus-Chatinet A, Florkin B, Gobert D, Lambotte O, De Somer L, et al. A survey of 90 patients with autoimmune lymphoproliferative syndrome related to TNFRSF6 mutation. Blood (2011) 118(18):4798-807. doi:10.1182/ blood-2011-04-347641

15. Straus SE, Jaffe ES, Puck JM, Dale JK, Elkon KB, Rosen-Wolff A, et al. The development of lymphomas in families with autoimmune lymphoproliferative syndrome with germline Fas mutations and defective lymphocyte apoptosis. Blood (2001) 98(1):194-200. doi:10.1182/blood.V98.1.194

16. Magerus-Chatinet A, Neven B, Stolzenberg MC, Daussy C, Arkwright PD, Lanzarotti N, et al. Onset of autoimmune lymphoproliferative syndrome (ALPS) in humans as a consequence of genetic defect accumulation. JClin Invest (2011) 121(1):106-12. doi:10.1172/JCI43752

17. Liu W, Putnam AL, Xu-Yu Z, Szot GL, Lee MR, Zhu S, et al. CD127 expression inversely correlates with FoxP3 and suppressive function of human CD4+ T reg cells. J Exp Med (2006) 203(7):1701-11. doi:10.1084/jem.20060772

18. Sakaguchi S, Sakaguchi N. Regulatory T cells in immunologic self-tolerance and autoimmune disease. Int Rev Immunol (2005) 24(3-4):211-26. doi:10.1080/ 08830180590934976

19. Sakaguchi S, Sakaguchi N, Asano M, Itoh M, Toda M. Immunologic selftolerance maintained by activated $\mathrm{T}$ cells expressing IL-2 receptor alphachains (CD25). Breakdown of a single mechanism of self-tolerance causes various autoimmune diseases. J Immunol (1995) 155(3):1151-64.

20. Caudy AA, Reddy ST, Chatila T, Atkinson JP, Verbsky JW. CD25 deficiency causes an immune dysregulation, polyendocrinopathy, enteropathy, X-linkedlike syndrome, and defective IL-10 expression from CD4 lymphocytes. J Allergy Clin Immunol (2007) 119(2):482-7. doi:10.1016/j.jaci.2006.10.007

21. Fontenot JD, Rasmussen JP, Gavin MA, Rudensky AY. A function for interleukin 2 in Foxp3-expressing regulatory T cells. Nat Immunol (2005) 6(11):1142-51. doi:10.1038/ni1263

22. Burchill MA, Yang J, Vang KB, Farrar MA. Interleukin-2 receptor signaling in regulatory $\mathrm{T}$ cell development and homeostasis. Immunol Lett (2007) 114(1):1-8. doi:10.1016/j.imlet.2007.08.005

23. Getnet D, Grosso JF, Goldberg MV, Harris TJ, Yen HR, Bruno TC, et al. A role for the transcription factor Helios in human CD4(+)CD25(+) regulatory T cells. Mol Immunol (2010) 47(7-8):1595-600. doi:10.1016/j.molimm.2010.02.001

24. Baine I, Basu S, Ames R, Sellers RS, Macian F. Helios induces epigenetic silencing of IL2 gene expression in regulatory T cells. J Immunol (2013) 190(3):1008-16. doi:10.4049/jimmunol.1200792

25. Thornton AM, Korty PE, Tran DQ, Wohlfert EA, Murray PE, Belkaid Y, et al. Expression of Helios, an Ikaros transcription factor family member, differentiates thymic-derived from peripherally induced Foxp $3+\mathrm{T}$ regulatory cells. J Immunol (2010) 184(7):3433-41. doi:10.4049/jimmunol.0904028

26. Himmel ME, MacDonald KG, Garcia RV, Steiner TS, Levings MK. Helios+ and Helios- cells coexist within the natural FOXP3 $\mathrm{T}$ regulatory cell 
subset in humans. J Immunol (2013) 190(5):2001-8. doi:10.4049/jimmunol. 1201379

27. Pandiyan P, Zheng L, Ishihara S, Reed J, Lenardo MJ. CD4+CD25+Foxp3+ regulatory $\mathrm{T}$ cells induce cytokine deprivation-mediated apoptosis of effector CD4+ T cells. Nat Immunol (2007) 8(12):1353-62. doi:10.1038/ ni1536

28. Miyara M, Chader D, Sage E, Sugiyama D, Nishikawa H, Bouvry D, et al. Sialyl Lewis X (CD15s) identifies highly differentiated and most suppressive FOXP3high regulatory T cells in humans. Proc Natl Acad Sci U S A (2015) 112(23):7225-30. doi:10.1073/pnas.1508224112

29. Banchereau J, Steinman RM. Dendritic cells and the control of immunity. Nature (1998) 392(6673):245-52. doi:10.1038/32588

30. Xiao S, Sung SS, Fu SM, Ju ST. Combining Fas mutation with interleukin-2 deficiency prevents colitis and lupus: implicating interleukin-2 for autoreactive $\mathrm{T}$ cell expansion and Fas ligand for colon epithelial cell death. J Biol Chem (2003) 278(52):52730-8. doi:10.1074/jbc.M308707200

31. Chinen T, Kannan AK, Levine AG, Fan X, Klein U, Zheng Y, et al. An essential role for the IL-2 receptor in Treg cell function. Nat Immunol (2016) 17(11):1322-33. doi:10.1038/ni.3540
32. Brusko TM, Wasserfall CH, Hulme MA, Cabrera R, Schatz D, Atkinson MA. Influence of membrane CD25 stability on T lymphocyte activity: implications for immunoregulation. PLoS One (2009) 4(11):e7980. doi:10.1371/journal. pone. 0007980

33. Maier LM, Anderson DE, Severson CA, Baecher-Allan C, Healy B, Liu DV, et al. Soluble IL-2RA levels in multiple sclerosis subjects and the effect of soluble IL-2RA on immune responses. J Immunol (2009) 182(3):1541-7. doi:10.4049/jimmunol.182.3.1541

Conflict of Interest Statement: The authors declare that the research was conducted in the absence of any commercial or financial relationships that could be construed as a potential conflict of interest.

Copyright (c) 2018 Mazerolles, Stolzenberg, Pelle, Picard, Neven, Fischer, MagerusChatinet and Rieux-Laucat. This is an open-access article distributed under the terms of the Creative Commons Attribution License (CC BY). The use, distribution or reproduction in other forums is permitted, provided the original author $(s)$ and the copyright owner are credited and that the original publication in this journal is cited, in accordance with accepted academic practice. No use, distribution or reproduction is permitted which does not comply with these terms. 